\title{
Metodologia e Técnicas para Análise de Artefatos e Narrativas
}

Daniele Ellwanger possui Graduação em Design pela Universidade Franciscana UFN (2004), Especialização em Design do Produto pela Universidade Luterana do Brasil - ULBRA (2006), Mestrado (2008) e Doutorado (2016) em Design pela Escola Superior de Desenho Industrial - ESDI, da Universidade do Estado do Rio de Janeiro - UERJ. Mantém vínculo empregatício como professora na Universidade Franciscana - UFN, no Curso de Design (desde março de 2009) e de Arquitetura e Urbanismo (em 2016), onde leciona várias disciplinas, além de ser orientadora de estágio e Trabalho Final de Graduação. Atua na especialização de Projeto de Espaços Comerciais, lecionando a disciplina de Ergonomia e Usabilidade, além de ser orientadora também. Atualmente, exerce o cargo de coordenadora do Curso de Design. Tem experiência na área de design, com ênfase em produto, atuando principalmente no campo de mobiliário. Possui publicações em anais de congressos, revistas e livros.

<daniele_ellwanger@hotmail.com> ORCID: 5676.1010 .8481 .4650
Resumo $O$ presente artigo buscou apresentar a metodologia utilizada na tese de doutorado realizada na ESDI/UERJ. Esta, por sua vez, visou analisar os artefatos trazidos, confeccionados ou adquiridos pelos imigrantes italianos, e como eles se faziam presentes na vida de seus descendentes. Assim, foram abordadas questões referentes às características que nortearam a imigração italiana no Brasil e no Rio Grande do Sul e o assentamento na região da Quarta Colônia. Na sequência, apontou-se a forma com que a metodologia adotada foi construída para que o estudo em questão se estabelecesse. Tal processo propiciou a catalogação e a classificação de mais de 300 artefatos, bem como a análise destes pelas dimensões interpretativas. Dessa forma, chegou-se aos resultados apresentados pelo cenário pesquisado, os quais proporcionaram a discussão sobre a metodologia e as técnicas adequadas para a realização de um exame detalhado de artefatos e narrativas.

Palavras chave Design de produto, Colônia italiana, Processo metodológico, Dimensões interpretativas. 
Lucy Niemeyer é Designer pela Escola Superior de Desenho Industrial - ESDI, da Universidade do Estado do Rio de Janeiro - UERJ, mestra em Educação pela Universidade Federal Fluminense - UFF, doutora em Comunicação e Semiótica pela Pontifícia Universidade Católica de São Paulo - PUC-SP, pós-doutora em Design pela Pontifícia Universidade Católica do Rio de Janeiro - PUC-RJ, como também pós-doutora em Design pela Unidade de Investigação em Design e Comunicação do Instituto de Arte, Design e Empresa - Universitário - UNIDCOM/IADE-U, em Lisboa, Portugal. É membro efetivo do CIAUD/ FAULisboa e da UNIDCOM/IADE, em Portugal. Professora da Escola de Belas Artes da Universidade Federal do Rio de Janeiro - UFRJ. Colabora com cursos de especialização em Design e em áreas correlatas. Sua atividade de investigação se expressa em livros de sua autoria, capítulos de diversos livros, artigos publicados em revistas indexadas e em anais de congressos científicos no Brasil e no exterior. <lucy.niemeyer@gmail.com> ORCID: 9230.5275 .8340 .0338

\section{Methodology And Techniques For Analysis Of Artifacts And Narratives}

Abstract The present paper sought to present the methodology used in the doctoral thesis held at ESDI/UERJ. This, in turn, aimed to analyze the artifacts brought in, made or acquired by Italian immigrants, and how they were present in the lives of their descendants. Thus, questions were raised regarding the characteristics that guided Italian immigration in Brazil and Rio Grande do Sul and the settlement in the region of Quarta Colonia. In the sequence, it was pointed out the way in which the adopted methodology was constructed so that the study in question was established. This process led to the cataloging and classification of more than 300 artifacts, as well as the analysis of these by interpretive dimensions. Thus, it reached the results presented by the researched scenario, which provided the discussion about the methodology and the appropriate techniques for performing a detailed examination of artifacts and narratives.

Keywords Product design, Italian colony, Methodological process, Interpretive dimensions. 


\section{Introdução}

Conforme a tese de Doutorado em Design intitulada "Design como Expressão da Capacidade Humana: estudo sobre os artefatos presentes na Quarta Colônia de imigração italiana, a partir de suas origens, particularidades e significados", realizada na Escola Superior de Desenho Industrial (ESDI), da Universidade do Estado do Rio de Janeiro (UERJ), o presente artigo buscou apresentar a metodologia utilizada para se analisar os artefatos trazidos, confeccionados ou adquiridos pelos imigrantes italianos e como eles se fizeram presentes na vida de seus descendentes. Considerou-se relevante a abordagem desse assunto porque se percebeu tal processo como uma nova maneira de se examinar os artefatos de um determinado período, bem como as narrativas que se revelaram a partir da imersão no contexto pesquisado.

Desse modo, pode-se realizar na tese um levantamento sobre os artefatos presentes na Quarta Colônia de imigração italiana, considerando o final do século XIX até o início do século XX; averiguar as origens desses objetos; distinguir os tipos de tecnologia empregados na sua confecção; estabelecer categorias para os artefatos pesquisados; identificar os seus diferentes usos em suas trajetórias; relatar a relação afetiva existente entre os descendentes e os objetos desenvolvidos até o início do século $\mathrm{XX}$, observando-os nos seus percursos.

Para discorrer sobre esse assunto, foi realizada uma pesquisa bibliográfica, fundamentada em fontes primárias e secundárias. 0 problema em questão pediu uma pesquisa qualitativa, tendo em vista a análise dos artefatos trazidos, confeccionados ou adquiridos pelos imigrantes italianos na região estudada, bem como de seus usos e significados no decorrer de seus trajetos. Para isso, realizou-se uma pesquisa de campo, onde a coleta de dados ocorreu por meio da aplicação de entrevista, sendo esta de característica estruturada, com roteiro previamente estabelecido, a qual, posteriormente, foi descrita. Outro instrumento de coleta deu-se pelo registro fotográfico de todos os artefatos encontrados. Após essa etapa, eles foram catalogados e classificados com base nas Normas de Inventários de Ciência e Técnica utilizadas pelos museus e palácios portugueses, bem como sua análise realizou-se a partir das dimensões interpretativas.

Assim, para este artigo, abordaram-se assuntos que envolveram uma breve história sobre a Quarta Colônia, para se entender o contexto estudado, bem como a descrição da metodologia e das técnicas adotadas na tese para o desenvolvimento das pesquisas bibliográfica e de campo. Ao final, os resultados foram apontados para que se chegasse, então, às conclusões deste trabalho.

\section{Uma Breve História sobre a Quarta Colônia}

De acordo com a política real portuguesa de aumentar o povoamento na região sul do Brasil, a fim de garantir a posse deste território e fazê-lo 
produtivo, coincidindo ainda com a superpopulação dos Açores, no início da segunda metade do século XVIII, os açorianos (de origem portuguesa) chegaram ao Rio Grande do Sul. A partir do início do século XIX, o governo imperial ${ }^{1}$ incentivou a vinda de alemães e, mais tarde, de italianos e poloneses, além de outros grupos étnicos europeus (ANTONELLO, 1996; BONI; COSTA, 1984).

Conforme Boni e Costa (1984, p. 25), a política de colonização foi dividida em três períodos, principalmente em relação ao Rio Grande do Sul:

a) a promoção da colonização (1808-1830);

b) a supressão da colonização devido à estabilização do sistema escravocrata (1830-1848);

c) incentivo à imigração - não à colonização - como forma de substituir a mão-de-obra africana (1848-1889).

Após a última fase, a imigração passou a ser espontânea (BATTISTEL; COSTA, 1983, p. 599).

Em 1824, então, colonos alemães chegaram à Província do sul, fato considerado como marco inicial da colonização no Brasil. A necessidade de mão-de-obra nos latifúndios monocultores, principalmente para o trabalho nos cafezais, em São Paulo, e, paralelamente, a crise socioeconômica da Itália promoveram a entrada, no Brasil, de imigrantes italianos somente em 1875 (BONI; COSTA, 1984, p. 27-31).

No Rio Grande do Sul, os italianos recebiam um lote e tornavam-se proprietários da terra, sendo o conjunto desses terrenos ocupados e construídos por italianos da mesma procedência. Com o passar dos anos, atingiram sua autonomia econômica, organizaram-se em sociedade e protegeram sua identidade étnica (BATTISTEL; COSTA, 1983, p. 599; ZANINI, 2006, p. 11).

Então, foram criadas as primeiras colônias para assentamento dos imigrantes, chamadas de Conde d'Eu ${ }^{2}$ e Dona Isabel ${ }^{3}$, atuais municípios de Garibaldi $^{4}$ e Bento Gonçalves ${ }^{5}$, respectivamente. Ainda em 1875, foi criada pelo Governo Geral a terceira colônia, chamada, primeiramente, de "Fundos de Nova Palmira", a qual foi rebatizada, em 1877, com o nome de "Caxias", região que compreende atualmente o município de Caxias do Sul (BATTISTEL; COSTA, 1982, p. 14).

Além dos altos da serra, muitos imigrantes foram direcionados às terras da Quarta Colônia Imperial de Silveira Martins ${ }^{6}$, em dezembro de $1877^{7}$, região próxima a Santa Maria da Boca do Monte, coração ou centro geográfico da, até então, Província. Essa ação, tomada pelo governo, na época, tinha como objetivo o povoamento das terras de mata próximas à atual cidade de Santa Maria, além de "proteger fronteiras e dinamizar mercados regionais" (ANTONELLO, 1996; BATTISTEL; COSTA, 1982, p. 14 e 187; BISOGNIN; RIGHI; TORRI, 2001, p. 57; VENDRAME, 2007, p. 26; ZANINI, 2006, p. 52). Chegando ao seu destino, os italianos instalaram-se no Barracão de Val de Buia, localizado ao pé da serra local. Mais tarde, eles tiveram que construir outros galpões para abrigar as demais levas de imigrantes que ali 
chegavam. Além do desolamento pela demora da entrega das terras, os imigrantes sofreram com uma peste epidêmica, que acabou trucidando cerca de 400 italianos em Val de Buia (ANTONELLO, 1996; BISOGNIN; RIGHI; TORRI, 2001, p. 60; ZANINI, 2006, p. 109).

Em 1878, foi autorizada, pelo governo, a divisão e distribuição dos lotes de terra, bem como foram fornecidas ferramentas necessárias para o plantio, como machado, foice, facão e enxada, além de sementes de feijão, milho e batata. Mesmo assim, tais indivíduos permaneceram, por muito tempo, abandonados e sem assistência médica. Após o recebimento dos lotes, os colonos abriam "uma clareira e armavam uma cabana com paus-a-pique, coberta de folhas de palmeira e que serviria de primeiro abrigo da família". A madeira das árvores derrubadas e as pedras de basalto ou arenito retiradas da região prestaram-se como materiais para a construção das casas (BISOGNIN; RIGHI; TORRI, 2001, p. 60; GUTIERREZ; GUTIERREZ apud MACHADO; SAAD; SAAD, 2012, p. 61; LORENZONI apud ZANINI, 2006, p. 118; ZANINI, 2006, p. 109).

No final de 1879, havia 1.465 italianos instalados na Quarta Colônia. Já em 1885, esse número subiu para 4.823. Nota-se que, em 1882, a Colônia de Silveira Martins foi emancipada do regime colonial, tornando-se, então, o 50 Distrito de Santa Maria. Sua emancipação ocorreu somente em 1987, desmembrando-se de Santa Maria (ANTONELLO, 1996; BISOGNIN; RIGHI; TORRI, 2001, p. 66 e 68).

Assim, a Quarta Colônia Imperial abrange, hoje, os municípios de Silveira Martins, Ivorá ${ }^{8}$, Nova Palma ${ }^{9}$, Faxinal do Soturno ${ }^{10}$, São João do Polêsine ${ }^{11}$, Dona Francisca ${ }^{12}$ e Pinhal Grande ${ }^{13}$. Atualmente, por questões político-econômicas, Agudo ${ }^{14}$, com colonização alemã, e Restinga Seca ${ }^{15}$, com colonização portuguesa, integram tal região, agora também conhecida por Quarta Colônia de Integração (Figura 1) (BENADUCE; MANFIO, 2010, p. 1; MACHADO; SAAD; SAAD, 2012, p. 58-60).

Fig 1. Cidades atuais que compõem a região da Quarta Colônia, localizada no centro do Estado do Rio Grande do Sul Fonte: IBGE apud BIANCHI (2007, p. 28)
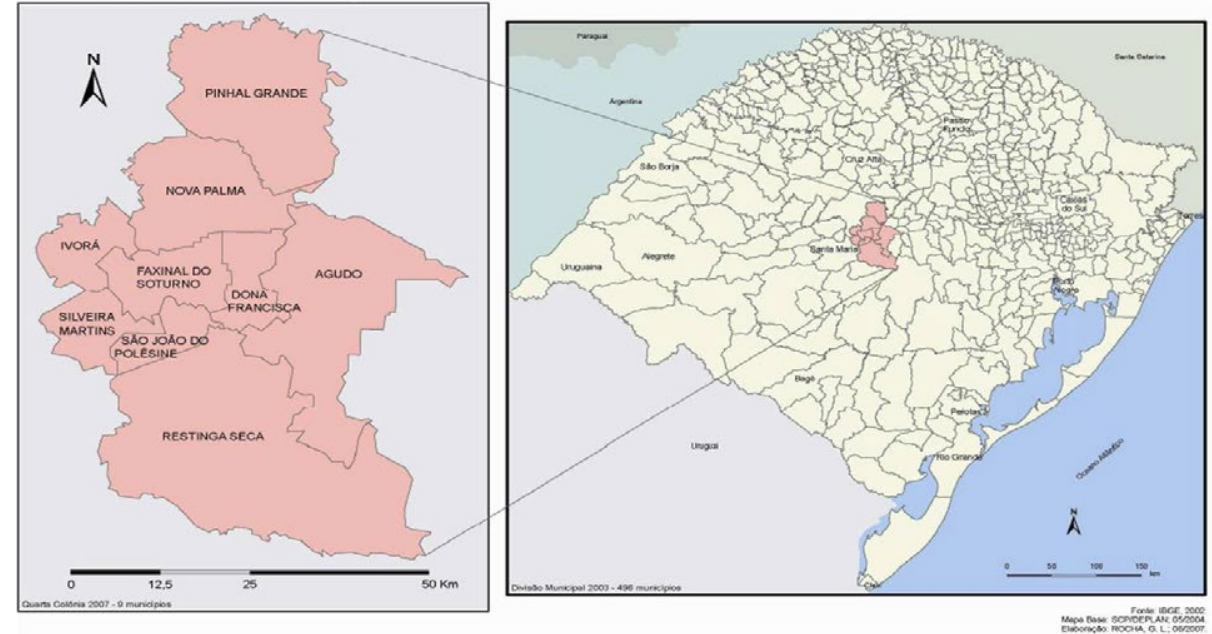


\section{Metodologia e Técnicas Adotadas na Tese de Doutorado}

Para a tese em questão, utilizou-se de uma articulação de técnicas, como estudo de documentários, revisão de literatura, documentação por meio de fotografias e áudio, análise visual, etc., a fim de se atingir os objetivos propostos. Ao se adotar uma variedade de técnicas, entendeu-se que se fez uso de uma metodologia semelhante à iniciada por Lévi-Strauss e desenvolvida por Denzin e Lincoln, a qual combina métodos originários das ciências sociais, humanas e naturais, que podem se adequar à investigação em design, à medida que atende à natureza indeterminada da disciplina (BREMMER; GRAY; MALINS; PIRIE; YEE; apud RODRIGUES, 2015, p. 169).

Assim, conjugaram-se procedimentos da metodologia qualitativa, caracterizada por experiências subjetivas (percepção, memória, afetividade, atividade social, etc.) e interpretações intuitivas, com procedimentos específicos, que resultaram no material empírico coligido, provindo do trabalho de campo. Desse modo, o estudo deu-se de forma indutiva, partindo do raciocínio particular ao geral, à medida que correlacionou os elementos estudados a fim de se entender o fenômeno.

Conforme consultas em Cruz e Ribeiro (2004), Gil (2012) e Lakatos e Marconi (1991), num primeiro momento, analisou-se o tema a partir de um levantamento preliminar de dados. Posteriormente, realizou-se pesquisa bibliográfica, fundamentada em fontes primárias, como sites da internet e documentários, e fontes secundárias, representadas por livros, artigos, monografia, dissertação e tese, por exemplo, para a elaboração da fundamentação teórica e demais capítulos.

O estudo foi realizado, então, por meio da metodologia qualitativa, como já mencionado, à medida que se analisaram os artefatos trazidos, confeccionados ou adquiridos pelos imigrantes italianos que se estabeleceram na região da Quanta Colônia, localizada no centro do atual Estado do Rio Grande do Sul, bem como seus usos e significados para as gerações que se sucederam. Nesse procedimento exploratório, a análise de dados compreendeu três etapas, conforme Huberman e Miles (apud GIL, 2012, p. 175-176): redução, exibição e conclusão/verificação. A primeira consistiu "no processo de seleção e posterior simplificação dos dados", conforme os objetivos da pesquisa; definiu-se "como codificar as categorias, agrupá-las e organizá-las para que as conclusões se [...] [tornassem] razoavelmente construídas e verificáveis". A segunda fase permitiu "a análise sistemática das semelhanças e diferenças e seu inter-relacionamento", o que pôde proporcionar "uma nova maneira de organizar e analisar as informações". A última etapa consistiu numa "revisão para considerar o significado dos dados, suas regularidades, padrões e explicações".

Para dar início à pesquisa de campo, entrou-se em contato com as secretarias dos sete municípios principais que compreendem a região da Quarta Colônia, a destacar: Silveira Martins, Ivorá, Nova Palma, Faxinal do Soturno, São João do Polêsine, Dona Francisca e Pinhal Grande. A pesquisa não se estendeu às cidades de Agudo e Restinga Seca, porque a primeira 
formou-se a partir do assentamento de imigrantes alemães e, a segunda, de portugueses. Das sete secretarias contatadas, obteve-se retorno de quatro (Ivorá, Nova Palma, Faxinal do Soturno, São João do Polêsine). Mas, por fim, a pesquisa de campo acabou se restringindo às cidades de São João do Polêsine, Ibarama (cidade vizinha à região) e Faxinal do Soturno.

A coleta de dados, então, deu-se pela aplicação de entrevista a seis descendentes de imigrantes. A obtenção das respostas ocorreu por entrevista pessoal à autora, registrada em forma de vídeo, com o mesmo equipamento utilizado para fotografar a maioria dos artefatos, conforme data estabelecida. $O$ roteiro de entrevista abordou assuntos referentes a dados pessoais; informações sobre o processo de imigração e o estabelecimento no Rio Grande do Sul, bem como sobre a cultura e os artefatos; informações atuais sobre a cultura e os bens; e especificamente sobre os artefatos. Os entrevistados assinaram o Termo de Consentimento Livre e Esclarecido. Cabe destacar que a elaboração do roteiro de entrevista tomou como base um questionário disponibilizado em Zanini (2006, p. 273). O instrumento de coleta de dados caracterizou-se pela entrevista estruturada e, segundo Lakatos e Marconi (1991, p. 197), "o entrevistador segue um roteiro previamente estabelecido; as perguntas feitas ao indivíduo são predeterminadas". Consideram-se as narrativas como importantes meios para se conhecer as experiências e os valores de determinados grupos. Elas circulam dentro da cultura, tratam sobre a própria cultura e, por conseguinte, sobre os objetos (WOODWARD apud RODRIGUES, 2015, p. 235).

Os participantes da pesquisa apresentaram, então, os artefatos pertencentes as suas famílias, todas de descendência italiana, alguns sob a forma de acervo pessoal (coleção). Além disso, teve-se acesso ao acervo do Museu Histórico Geringonça, o qual possui peças que foram doadas, a maioria, por famílias descendentes de imigrantes italianos. Em geral, os artefatos foram fotografados com uma câmera digital semiprofissional, apoiada num tripé, de propriedade da própria autora (alguns foram fotografados por Pablo Zambeli, profissional de fotografia); colocados sobre um pano de fundo rústico e fazendo-se uso de uma régua de $30 \mathrm{~cm}$ como referência para se fixar a proporcionalidade entre os mesmos. A catalogação dos artefatos teve como base as Normas de Inventários de Ciência e Técnica utilizadas pelos museus e palácios portugueses, bem como sua análise deu-se a partir das dimensões interpretativas, propostas por Rodrigues (2015).

\section{Normas de Inventário como Ferramenta para Catalogação e Classificação} dos Artefatos

Por conta da infindável diversidade de material identificado a partir da pesquisa de campo, sentiu-se a necessidade de se realizar uma seleção e uma catalogação dos mais variados utensílios, ferramentas, etc.. As dificuldades residiam na definição e estruturação dos campos do fichamento de cada item selecionado. Para tanto, a pesquisadora Giane Vargas Escobar, doutoranda em Museologia pela Universidade Federal de Santa Maria 


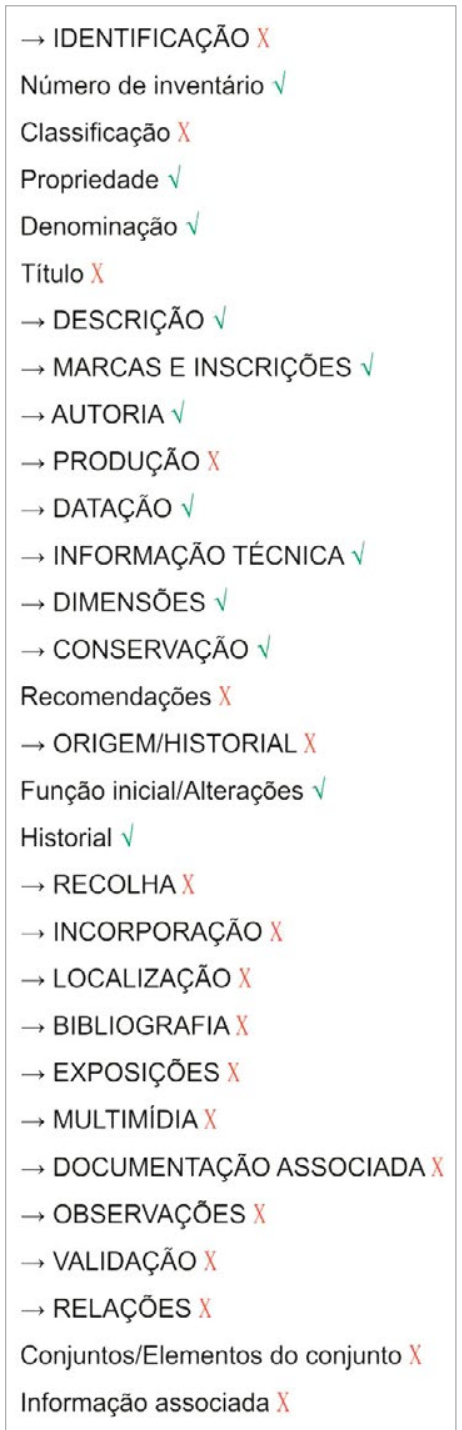

Fig 2. Campos de fichamento utilizados pelos museus e palácios portugueses e seleção daqueles pertinentes à pesquisa Fonte: COSTA e cosTA (2010)
(UFSM), recomendou como referências para o desenvolvimento da catalogação e da classificação dos artefatos as Normas de Inventários de Ciência e Técnica adotadas pelos museus e palácios de Portugal. A adoção por tais instituições deu-se a partir da "introdução do sistema Matriz nos museus do Instituto dos Museus e da Conservação (IMC)", em 1993, a fim de se refletir "sobre as especificidades conceptuais e terminológicas do património [sic]" dos mesmos. Esse sistema tem como intuito o fichamento padronizado, em formato digital, das coleções dessas entidades, por meio de tecnologias da informação. Desde 2000, via motor de pesquisa MatrizNet, pode-se ter acesso aos inventários pela internet. Já o MatrizPix, lançado em 2008, consiste num sistema de informação on-line que disponibiliza imagens produzidas e/ou geridas pelo IMC (COSTA; COSTA, 2010, p. 15, 24, 28 e 30- 31).

Para inventariar suas coleções, os museus e palácios portugueses empregaram os campos de fichamento, os quais foram apresentados na Figura 2, ao lado. Desses, selecionaram-se aqueles mais relevantes e pertinentes à pesquisa em questão.

A partir disso, pôde-se realizar uma descrição detalhada dos artefatos, conforme a simplificação apresentada na Figura 3, contemplando os seguintes campos: foto no, tipo, função, lugar de origem, data, proprietário, fabricante, partes, materiais, técnica de fabricação, medidas gerais e marcas. Tais aspectos tomaram por base as definições dos campos selecionados a partir das Normas de Inventário.

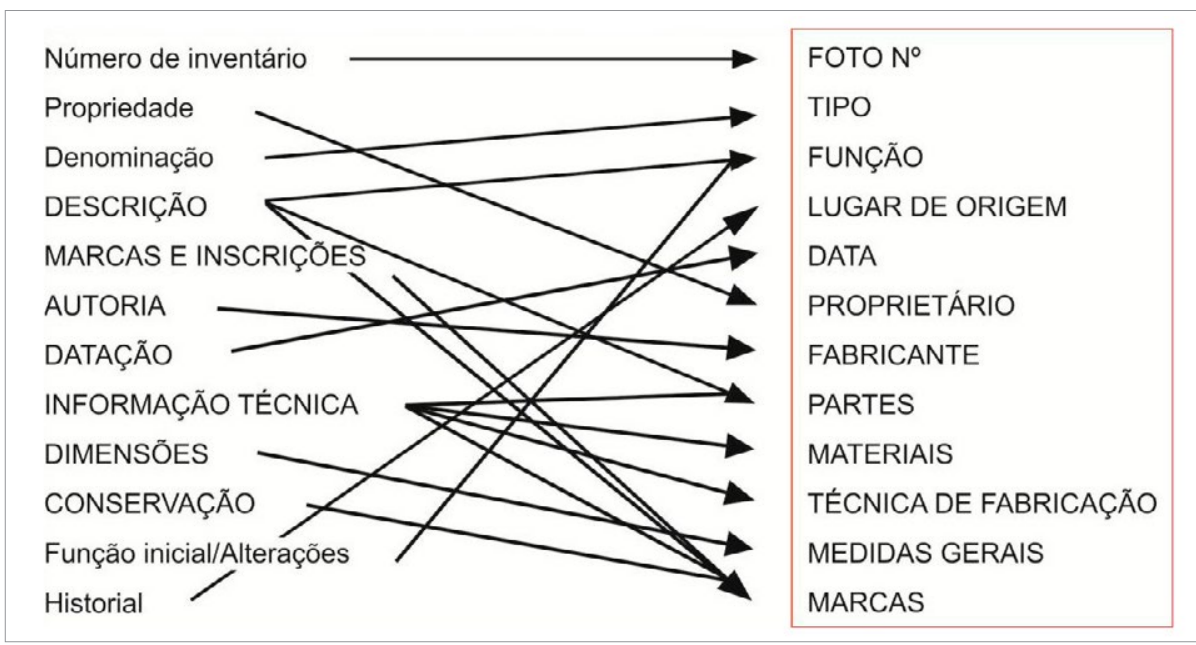

Fig 3. Aspectos selecionados e simplificados para descrição de cada artefato Fonte: coleção da autora (2016)

Assim, desse estudo resultou a catalogação com um total de 318 artefatos descritos, relacionados aos seus atuais proprietários. No Quadro 1, tem-se a descrição de um artefato como exemplo. 


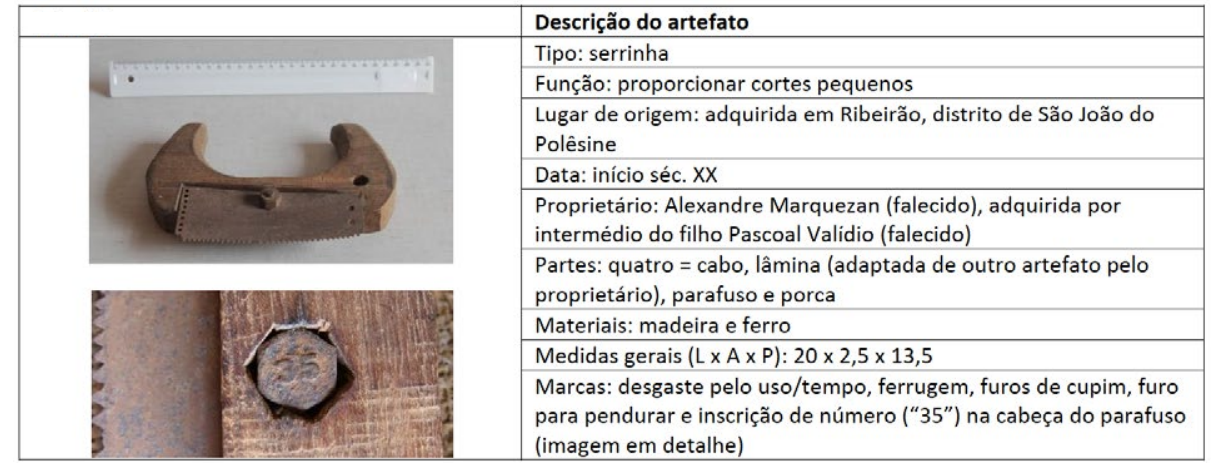

Quadro 1. Descrição de um artefato

Fonte: coleção da autora (2015)

Após o término dessa primeira etapa, verificou-se a necessidade de se classificar essa diversidade de artefatos, conforme suas afinidades e semelhanças. As Normas de Inventário forneceram subsídios para que se identificasse, por meio de uma macroanálise, que tal material poderia ser classificado em categorias, de acordo com o seu principal meio de obtenção: artesanal, semi-industrial ou industrial. A partir disso, realizou-se uma microanálise, em que se puderam definir subcategorias, sendo as mesmas para cada categoria, segundo a principal utilização do artefato, as quais correspondem a: artefatos para manufatura ou trabalho pesado, artefatos para atividade agropecuária, mobiliário, utensílios para cozinha, utilidades domésticas e outros. Tal classificação pode ser observada na Figura 4.

ARTESANAL

Fig 4. Categorias e subcategorias para classificação dos artefatos

Fonte: coleção da autora (2016)

Método para Análise dos Artefatos e das Narrativas

A partir de Rodrigues (2015, p. 212-213), buscou-se analisar os artefatos e as narrativas por meio das Dimensões Interpretativas, mas sob uma ótica diferenciada. A referida autora adotou em sua tese as seguintes dimensões: funcional, operativa, semântica, emocional/evocativa, sensorial/ experimental, social, onírica/superação de limites. Para a tese em questão, 
optou-se por considerar a dimensão funcional, associada à operativa, chamada, então, de Dimensão Funcional/Usual/Indicial; a dimensão emocional/evocativa, neste trabalho entendida por Dimensão Afetiva/Evocativa; e a Dimensão Temporal/Espacial, criada para complementar este estudo. As Dimensões Temporal/Espacial e Funcional/Usual/Indicial referiram-se às interpretações relativas aos artefatos. Já a Dimensão Afetiva/Evocativa direcionou-se à relação entre os artefatos e os indivíduos, no caso, entre os objetos pertencentes ou sob os cuidados dos participantes da pesquisa em questão.

A Dimensão Temporal/Espacial referiu-se às origens dos artefatos, em quais países foram confeccionados ou onde foram adquiridos, e em que época tais situações sucederam-se. A Dimensão Funcional/Usual/Indicial contemplou as particularidades dos artefatos pesquisados, sob uma perspectiva exclusivamente instrumental e física, em termos de funções, usabilidade, bem como de marcas de fabricantes, autorais ou acarretadas pelo uso e/ou pelo tempo. Já a Dimensão Afetiva/Evocativa descreveu o que os artefatos faziam lembrar os indivíduos, os quais evocavam memórias e/ou etapas marcantes da vida pessoal, e despertavam emoções, além dos significados que foram adquirindo no decorrer dos anos, diferentemente dos papéis aos quais tinham sido destinados (RODRIGUES, 2015, p. 20, 64 e 213).

Essas dimensões interpretativas permitiram "considerar e comunicar de forma integrada diversos tipos de conhecimento implícito nos artefatos". Assim, eles puderam "ser vistos como respostas a questões de investigação, como argumentos e como métodos para coligir e preservar informação e compreensão", à medida que foram entendidos como repositórios de conhecimento(s), pois houve "evidência do conhecimento e saber envolvido na sua concepção e produção armazenadas no objecto [sic]", bem como de valor(es). Além disso, os artefatos também incorporaram a identidade individual e o conhecimento pessoal do ser humano, o qual foi adquirido por meio da relação com a dimensão material da vida (MÄKELÄ apud RODRIGUES, 2015, p. 239; RODRIGUES, 2015, p. 244).

\section{Resultados e Discussão}

Por meio da metodologia e técnicas adotadas, pôde-se identificar, por exemplo, que apenas alguns exemplares vieram da Itália, mas considerou-se que, dentre os objetos classificados, havia mais artefatos que foram trazidos pelos italianos, o que não era garantido simplesmente porque tais objetos já tiveram sucessivos donos ou já passaram por várias gerações, e os últimos proprietários não tinham certeza sobre suas origens.

Os artefatos confeccionados pelos primeiros imigrantes foram feitos para atenderem ao consumo imediato, relacionado, essencialmente, a questões funcionais, as quais corresponderam à premência de se possuir instrumentos para a obtenção de outros ou para a realização de tarefas árduas, bem como daqueles que serviam ao trabalho e às lidas domésticas, a fim de suprirem as necessidades básicas de sobrevivência, ou seja, eram, so- 
bretudo, bens de produção. Com os excedentes da produção agropecuária, que ultrapassavam o necessário para o consumo próprio, a região da Quarta Colônia começou a prosperar, o que permitiu a renovação dos sistemas produtivos e a aquisição de novos artefatos.

Assim, observou-se que, até o final da década de 1910, houve uma prevalência de material artesanal, já com a presença de alguns artefatos resultantes de processo semi-industrial. Depois desse período, os produtos que vieram a substituir aqueles rudimentares tiveram, como meio de obtenção, a produção industrial. Então, a evolução de um mesmo tipo de artefato foi observada por meio da análise realizada nesse trabalho, em que peças obtidas por diferentes processos de obtenção, sejam eles artesanal, semi-industrial e industrial, eram destinadas a realizarem a mesma função.

A maioria dos artefatos classificados na pesquisa foram dados por conhecidos e foram adquiridos pelos seus atuais proprietários no Estado do Rio Grande do Sul, principalmente dentro da região da Quarta Colônia. Alguns possuíam inscrições quanto a sua origem específica, as quais informavam em que municípios ou Estados do Brasil, ou mesmo em outros países, foram confeccionados. Infelizmente, não se teve conhecimento de como esses objetos chegaram até tal região. Encontraram-se diferenças formais e estruturais nos artefatos oriundos de diferentes localidades, causadas, principalmente, pelos meios de obtenção das mesmas também serem diferentes. Percebeu-se também que, mesmo possuindo as mesmas funções, as peças poderiam variar quanto à estrutura e à forma. Assim, alguns desses objetos vieram da Itália, ou foram confeccionados a partir de registros de memória, o que determinou a variação nas suas características, isso como decorrência dos materiais disponíveis e dos processos de obtenção possíveis na época.

A pesquisa de campo propiciou também a percepção de que a maioria dos artefatos classificados compreendeu aqueles de feitura artesanal. Acreditou-se que houve incidência maior de modelos artesanais porque se encontravam obsoletos e fora de uso, visto que foram substituídos por novas tecnologias, os quais compõem, agora, as coleções pertencentes aos participantes da pesquisa.

Contudo, os detalhes, as marcas, as particularidades de determinados artefatos transpareceram suas origens, seus fabricantes, seus meios de obtenção, suas funções e seus usos. Outros elementos foram importantes para o seu entendimento, como os atributos estético- formais e os componentes de segurança, por exemplo. Além disso, a maioria dos artefatos apresentaram desgastes, como amassados, degradações dos materiais, ferrugens, entre outros, pelo uso ou pelo tempo, até porque, alguns deles tinham mais de um século de existência, assim como furos de cupim em partes que os integram.

Ao analisar os artefatos sob outra perspectiva, percebeu-se que eles possuíram um significado num certo momento, e que este se transformou com o passar do tempo. Logo que as famílias começaram a prosperar, os objetos resultantes do fazer artesanal passaram a ser motivo de vergonha 
por representarem o período inicial de dificuldades pelo qual passaram e, por isto e quando possível, foram substituídos por novos produtos, mais confortáveis e eficientes para os seus afazeres. Segundo Alberti (2014), aos objetos antigos, então, não se dava mais importância, não se tinha o pensamento de guardá-los, eram descartados. Já outras famílias valorizavam os artefatos adquiridos e guardavam-nos. Assim, por meio das mensagens assimiladas através de suas memórias, foi sendo construída pelos descendentes uma nova rede de valores, significados e importâncias atribuídas aos objetos do seu entorno.

Os objetos tornaram-se relíquias, tornaram-se coisas sagradas, os quais representaram símbolo de pertencimento e referência identitária. Assim, aquela vergonha sentida pelos imigrantes e seus descendentes, por conta da pobreza e da precariedade inicial vivida, cedeu lugar, a partir da década de 1990, a outra forma de interpretação desses objetos, mais prazerosa e portadora de valor, afeto e dignificação. Aqueles expostos nas casas, como coleções, possuem significados que estão em constante reelaboração, elementos esses que rememoram as experiências familiares.

Por proporcionarem lembranças, tais objetos passaram a ser repositórios de histórias, ao mesmo tempo em que incorporaram as histórias das pessoas. Dessa forma, essas peças passaram a representar orgulho, como relatou a maioria dos entrevistados, em função das adversidades que seus ancestrais vivenciaram para alcançar condições melhores de vida, além do enorme valor sentimental que sentiam por tais objetos, à medida que os faziam lembrar seus antepassados. Para os filhos e netos, pertencentes à quarta ou quinta geração de descendentes de italianos, esses artefatos despertavam a curiosidade em saber para que serviam, como funcionavam, o que demonstrou o interesse pelas coisas antigas e pelas vivências de seus ancestrais.

\section{Considerações Finais}

A partir da metodologia e das técnicas utilizadas, concluiu-se que houve dois momentos importantes de mudança em relação aos meios de obtenção de artefatos que foram encontrados na região da Quarta Colônia: o primeiro se deu logo após a chegada dos imigrantes italianos à localidade, em 1877, quando deram início a uma produção praticamente genuína resultante do fazer artesanal, para atender ao consumo imediato e às necessidades básicas de sobrevivência; enquanto que, depois de 1920, os produtos resultantes do processo industrial surgiram para substituir aqueles rudimentares. Cabe observar que artefatos obtidos por intermédio do sistema semi-industrial já circulavam desde o final do século XIX e início do século XX na região.

Dessa forma, percebeu-se a ocorrência da combinação de artefatos compostos por determinadas características, muitas vezes diferentes entre si, provenientes de tecnologias e épocas distintas. Isso fez com que os imigrantes e seus descendentes atribuíssem novos usos e significados aos 
primeiros objetos elaborados. Diante da análise apresentada, notou-se que, realmente, é possível compreender os elementos do acervo estudado para além de suas funções e tecnologias, pois eles são portadores de informações ainda pouco exploradas, ou seja, os artefatos devem ser entendidos como repositórios de conhecimento(s), pois contêm aspectos ligados a sua concepção, bem como valores, que servem como respostas a questões de investigação de uma cultura, do pensar e do fazer humanos.

Assim, a metodologia apresentada presta-se a outras reflexões que poderão ser objeto de outras pesquisas. Desse modo, poderá haver relevante contribuição para o aprofundamento e ampliação da construção do conhecimento na área do design.

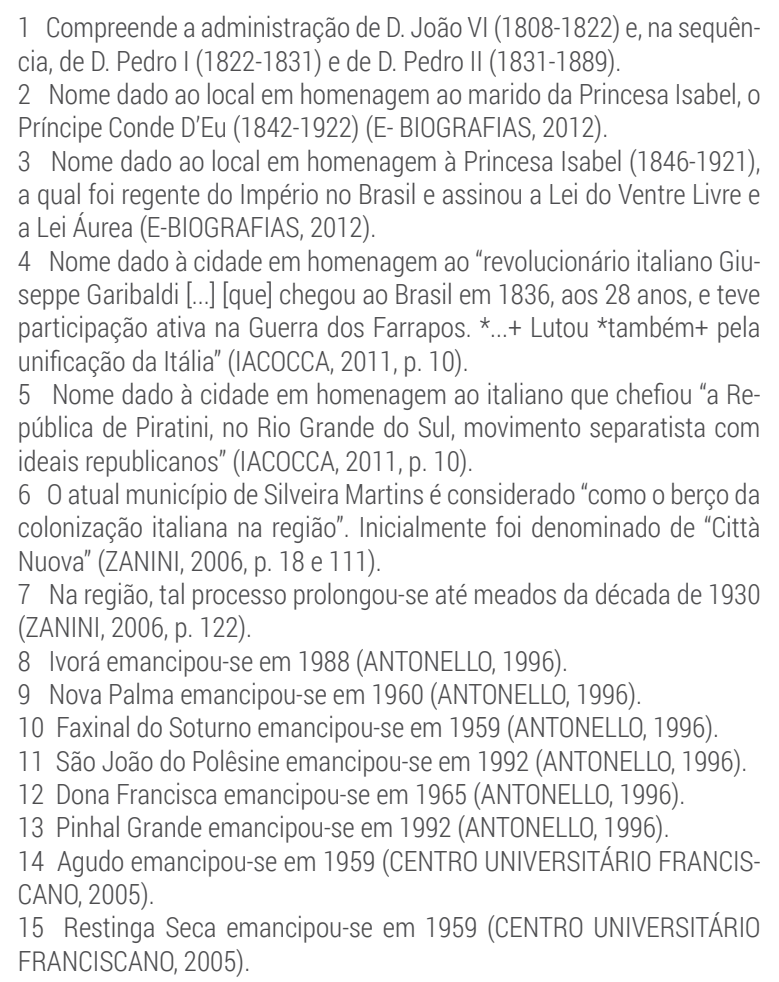

\section{Referências}

ALBERTI, Adrioni Antonio. Entrevista degravada, com duração de 30 minutos. São João do Polêsine: 02 de julho de 2014.

ANTONELLO, Idê Vitoria. Emigração na Itália e imigração italiana no Brasil e no Rio Grande do Sul. Santa Maria, RS: 1996. $60 \mathrm{fl}$.

BATTISTEL, Arlindo Itacir; COSTA, Rovílio. Assim vivem os italianos: religião, música, trabalho e lazer. Porto Alegre: Escola Superior de Teologia São Lourenço de Brindes e Editora da Universidade de Caxias, 1983.

. Assim vivem os italianos: vida, história, cantos, comidas e estórias. Porto Alegre: Escola Superior de Teologia São Lourenço de Brindes e Ed. da Universidade de Caxias, 1982. 
BENADUCE, Gilda Maria Cabral; MANFIO, Vanessa. A Quarta Colônia de imigração italiana: a valorização cultural da região. In: XIV Simpósio de Ensino, Pesquisa e Extensão - SEPE: Responsabilidade Socioambiental. Anais. Santa Maria: Centro Universitário Franciscano, 2010. v. 1. Disponível em: <http://www.unifra.br/eventos/sepe2010/2010/trabalhos/humanas/ Completo/4596.pdf>. Acesso em: 06 abr. 2014.

BIANCHI, Ana Cristina. Avaliação de propostas públicas municipais e regionais no âmbito do planejamento integrado do turismo sustentável na Quarta Colônia, RS, Brasil. 2007. 161 p. Dissertação (Mestrado em Desenvolvimento Regional), Universidade de Santa Cruz do Sul UNISC, Santa Cruz do Sul, 2007. Disponível em: <http://btd.unisc.br/Dissertacoes/AnaBianchi.pdf>. Acesso em: 07 abr. 2014.

BISOGNIN, Edir Lucia; RIGHI, José Vicente; TORRI, Valmor. Povoadores da Quarta Colônia. Porto Alegre: EST, 2001.

BONI, Luís Alberto De; COSTA, Rovílio. Os italianos do Rio Grande do Sul. 3. ed. Porto Alegre: Escola Superior de Teologia São Lourenço de Brindes; Caxias do Sul: Universidade de Caxias do Sul, Correio Riograndense; 1984.

CENTRO UNIVERSITÁRIO FRANCISCANO. Projeto de organização e informatização do acervo da Quarta Colônia. 2005. Disponível em: <http://www.unifra.br/home/Noticia.asp?625>. Acesso em: 06 abr. 2014.

COSTA, Marta Sanches da; COSTA, Paulo Ferreira da. Normas de inventário: ciência e técnica - normas gerais. 2010. Disponível em: <http://www.matriznet.dgpc.pt/MatrizNet/Download/Normas/NI_Ciencia_Tecnica.pdf>. Acesso em: 10 set. 2015.

CRUZ, Carla; RIBEIRO, Uirá. Metodologia científica: teoria e prática. 2. ed. Rio de Janeiro: Axcel Books do Brasil, 2004.

E-BIOGRAFIAS. Princesa Isabel: Monarca brasileira. 2012. Disponível em: <http://www.ebiografias.net/princesa_isabel/>. Acesso em: $12 \mathrm{dez} .2013$.

GIL, Antonio Carlos. Métodos e técnicas de pesquisa social. 6. ed. São Paulo: Atlas, 2012. IACOCCA, Angelo. Retratos da imigração italiana no Brasil. Traduzido por Cipriana Leme. São Paulo: Editora Brasileira de Arte e Cultura, 2011.

LAKATOS, Eva Maria; MARCONI, Marina de Andrade. Fundamentos da metodologia científica. 3. ed. São Paulo: Atlas, 1991.

MACHADO, Marcos Vinicios Machado; SAAD, Danielle de Souza; SAAD, Denise de Souza. Quarta Colônia de imigração italiana, patrimônio cultural e turismo no planalto central do Rio Grande do Sul, no sul do Brasil. Revista América Patrimonio, Patrimonio y Turismo, Santiago de Chile, n. 4, p. 54-68, segundo semestre 2012. Disponível em: <http://www.revistaamericapatrimonio.org/revista_america_patrimonio_4/files/publication.pdf>. Acesso em: 06 abr. 2014.

RODRIGUES, Paula Maria de Azevedo Ferreira. Design e conhecimento: uma leitura antropológica dos artefactos (documento provisório). 2015. 393 p. Tese (Doutorado em Design), Universidade de Aveiro, Aveiro, 2015.

VENDRAME, Maíra Ines. "Lá éramos servos, aqui somos senhores": a organização dos imigrantes italianos na ex-Colônia Silveira Martins (1877-1914). Santa Maria: Ed. da UFSM, 2007. 322 p. ZANINI, Maria Catarina Chitolina. Italianidade no Brasil meridional: a construção da identidade étnica na região de Santa Maria-RS. Santa Maria: UFSM, 2006.

Recebido: 04 de setembro de 2018. Aprovado: 11 de setembro de 2018. 